\title{
Contabilidade em emergia de dois sistemas de geração de energia elétrica com utilização de resíduos
}

Corsini, I.a; Carvalho, B. S.b; Pereira, E. M.c, Cunha, M. C. A.d, Silva, C.C.e a, b, c, d e e. IFSULDEMINAS, Inconfidentes-MG, corsini.igor@gmail.com

\section{RESUMO}

Este artigo tem como objetivo avaliar através da contabilidade em emergia, dois sistemas de produção de energia elétrica. Comparando duas realidades distintas, uma que utiliza um sistema de geração de energia instalado em uma usina autônoma no Estado de São Paulo e outra em uma Estação de Tratamento de Esgoto (ETE) situada em Uppsala, Suécia. Os sistemas foram mensurados através de indicadores que indicam a carga ambiental.

Esta metodologia apresenta resultados sintéticos e de fácil entendimento que auxiliam na busca do desenvolvimento sustentável e ambientalmente correto. Com base em nossas análises o sistema de biodigestão instalado na estação ETE, indica desvantagens em relação a usina autônoma.

Isso se deve ao superior aproveitamento que a usina autônoma faz dos recursos renováveis $(\mathrm{R}, \mathrm{N})$, tendo assim melhor transformidade, menor carga ambiental e menor pressão sobre o meio ambiente.

Palavras chave: emergia, ETE, usina autônoma, resíduos, energia

\section{Emergy Accounting in the two systems of generating electricity using waste}

\section{ABSTRACT}

This article aims to assess by emergy accounting, two systems of electric power production. Comparing two different realities, one that uses a power generation system installed on a standalone mill in São Paulo and another in a Sewage Treatment Station (STS) located in Uppsala, Sweden. The systems were measured by indicators that indicate the environmental burden.

This methodology presents the results, synthetic and easy to understand that aid in the pursuit of sustainable development and environmentally friendly. Based on our analysis of the digestion system installed at the station ETE indicates disadvantages over the plant unattended.

This is due to higher utilization that makes the plant independent of renewable resources $(\mathrm{R}, \mathrm{N})$, thus Transformity better, lower environmental burden and reduced pressure on the environment.

Key words: emergy, STS, independent power plant, waste, energy

\section{INTRODUÇÃO}

A busca de fontes de energia renovável é um dos grandes pontos para obtermos sistemas ambientalmente viáveis.

Este estudo realiza a comparação dos indicadores de emergia de dois sistemas de aproveitamento de resíduos na geração de energia elétrica, com a finalidade de identificar sistemas que utilizem fontes renováveis para produção de energia elétrica. 
Através da análise dos indicadores em emergia foi possível mensurar a utilização dos recursos de natureza substancialmente diferentes: Renováveis (R), Não Renováveis $(\mathrm{N})$ e de fontes pagas $(\mathrm{F})$

A energia elétrica pode ser produzida por diversos sistemas, tendo em vista a sustentabilidade ambiental, é de crucial importância que busquemos os meios ambientalmente menos impactantes.

O estudo avalia dois sistemas: um utiliza como fonte energética resíduos agrícolas de uma usina sucroalcoleira autônoma e o outro resíduos urbanos da cidade de Uppsala, Suécia.

\section{Definição dos Sistemas}

Sistema da usina autônoma (SILVA, 2009), idealizada em uma área de 4.360 ha, onde 1.494 ha são utilizados para o plantio de cana, produzindo 40.000 litros de álcool diários, e 27,1 kWh de eletricidade excedente por tonelada de cana utilizando uma caldeira de $67 \mathrm{bar} / 480^{\circ} \mathrm{C}$, operando durante 210 dias ao ano.

ETE (Bjorklund et al, 2001): Estação de tratamento de esgoto que trata situada na cidade de Uppsala, Suécia, que trata de $100.000 \mathrm{~m}^{3}$ de esgoto anualmente em sistema de Lodo Ativado.

\section{Metodologia}

\subsection{Emergia}

A Emergia (memória energética) é utilizada como ferramenta do presente estudo com base nos conceitos apresentados por Odum (1996). O valor da emergia total incorpora todos os recursos e serviços utilizados para obtenção de um produto, processo ou serviço, sejam estes recursos provenientes do meio ambiente ou da economia. Para a análise, são construídos diagramas de energia para identificar todos os fluxos de material e energia que constituem o sistema. Esta metodologia utiliza uma álgebra própria, com a qual é possível calcular indicadores, a partir das relações entre as fontes de recursos que compõem o sistema estudado. As relações identificadas no diagrama de energia são construídas com os símbolos da Fig. 1.

A unidade da emergia é o joule de emergia solar, que permite contabilizar os fluxos provenientes do meio ambiente e da economia com uma base comum, sej (solar emergy joules). A transformidade, sej/J, define a quantidade de emergia (sej) necessária para a obtenção de um joule de um produto, processo ou serviço, seja ele natural ou antropogênico. Uma vez determinada a transformidade de um produto, torna-se possível calcular a energia solar direta e indireta necessária para sua obtenção.

A contabilidade considera tanto os recursos utilizados para a implantação dos processos como aqueles empregados durante sua operação. Uma vez determinada a transformidade de certo número de produtos, torna-se possível calcular em cascata, a energia solar indireta necessária para se obter outro produto, processo ou serviço.

Brown e Mcclanahan (1996) sintetizaram de maneira prática e eficaz as etapas para observação e avaliação de um sistema produtivo com o uso da contabilidade em emergia. Identificando as entradas requeridas para a implantação e a operação de cada processo, mostraram como construir um diagrama de energia, as tabelas de emergia e como desenvolver a síntese em emergia. 


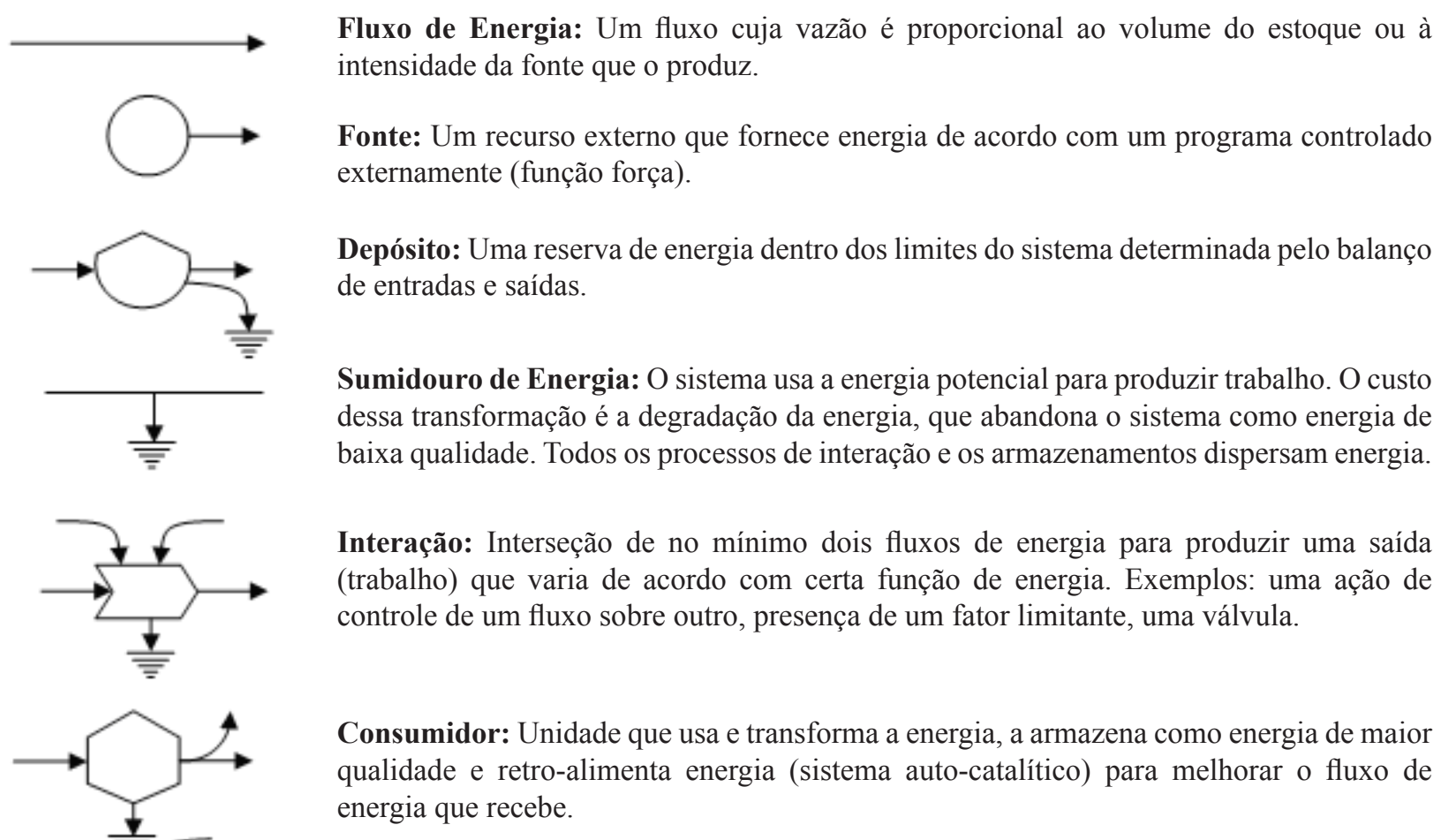

Interruptor: Um sistema de acionamento ou corte de um fluxo de energia de acordo com a ação de uma ou mais energias de controle.

Produtor: Unidade que coleta e transforma energia de baixa intensidade sob a ação de um ou mais fluxos de energia de alta qualidade.

Receptor de energia autolimitante: Uma unidade com saída autolimitada. Mesmo que de forças externas sejam altas, existe um círculo interno de energia que está controlado pela presença limitada de um material de alta qualidade.

Caixa: Símbolo de uso múltiplo que pode ser usado para representar uma unidade de consumo e produção dentro de um sistema maior. Representa um sub-sistema.

Amplificador de ganho constante: Uma unidade que fornece uma saída proporcional a uma entrada de energia, mas que pode ser modificada por um fator de ganho, contanto que a fonte de energia $\mathrm{S}$ seja capaz de fornecer energia.

Transação: Um intercâmbio de recursos. Venda de bens ou serviços (linha contínua) em troca de um pagamento em dinheiro (linha tracejada). O preço é mostrado no símbolo como fonte de energia externa.

Figura 1. Símbolos para utilização nos diagramas em emergia (Odum,1996). 
Giannetti et al (2006) desenvolveram uma ferramenta gráfica que produz um diagrama triangular eqüilátero com três variáveis associadas a porcentagens, ao qual atribuem o nome de diagrama em emergia ternário.

Cada vértice do triângulo está associado a um fluxo renovável $(\mathrm{R})$, não renovável $(\mathrm{N})$ e proveniente da economia (F) e os lados do triângulo representam combinações binárias. As combinações dos três fluxos são representadas por pontos no interior do triângulo e o valor percentual de cada fluxo é dado pela perpendicular que une o ponto e a lateral oposta ao vértice de interesse, onde é possível representar três variáveis em duas dimensões. Uma descrição completa da ferramenta gráfica é encontrada em (BARRELLA et al, 2005, ALMEIDA et al, 2005 e GIANNETTI et al, 2006).

O uso das propriedades dos triângulos eqüiláteros fornece informações adicionais sobre a dependência do sistema em estudo em um determinado tipo de fluxo ( $\mathrm{R}, \mathrm{N}$ ou F), sobre a (eco)eficiência do sistema, quanto ao uso de reservas e sobre a eficiência do suporte do ambiente, necessário à operação do sistema. A ferramenta gráfica permite comparar sistemas, produtos, processos e serviços, como também avaliar melhorias e acompanhar o desempenho do sistema ao longo do tempo. Com o auxílio dos diagramas, podem-se avaliar interações entre sistemas ou o desempenho de um setor industrial e as interações de sistemas ou do setor com o ambiente.

\section{Indicadores}

Os indicadores utilizados foram desenvolvidos por Odum (1996). O rendimento em emergia (EYR), o investimento em emergia (EIR), o índice de carga ambiental (ELR). Além destes indicadores foi também calculado o índice de sustentabilidade (ESI). O ESI, proposto por Ulgiati e Brown (1998), apresenta a razão entre EYR e ELR. O percentual de emergia renovável (\%R) também é utilizado para comparar os sistemas de geração de energia. Na Tabela 1 apresentam-se as equações para o cálculo dos indicadores, assim como uma breve descrição de sua utilização.

Tabela 1. Indicadores em emergia utilizados neste estudo.

Tabela 1. Apresentação e descrição dos indicadores da síntese em emergia.

\begin{tabular}{|c|c|c|}
\hline Descrição & Indicador & Equação \\
\hline $\begin{array}{l}\text { Rendimento em emergia (emergy yield ratio): É a relação entre a emergia total contida no produto } \\
\text { (Y) em relação aos recursos provenientes da economia (F), ou seja, é a emergia do sistema dividido } \\
\text { pela entrada dos fluxos de emergia provenientes da economia. È um indicador de retorno de energia } \\
\text { sobre o investimento realizado, fornecendo a emergia líquida do sistema, ou seja a contribuição da } \\
\text { emergia proveniente do sistema de produção }(\mathrm{R}+\mathrm{N}) \text {. Demonstra a capacidade do processo para } \\
\text { explorar os recursos locais provenientes da natureza. O valor mínimo é a unidade. }\end{array}$ & \multicolumn{2}{|c|}{$\begin{array}{l}\text { EYR } \quad \mathrm{Y} / \mathrm{F} \\
\qquad(\mathrm{R}+\mathrm{N}+\mathrm{F}) / \mathrm{F}\end{array}$} \\
\hline $\begin{array}{l}\text { Índice de carga ambiental (environmental loading ratio): É definido como a relação entre emergia } \\
\text { de entrada dos recursos locais não renováveis e de recursos provenientes da economia pela emergia } \\
\text { do recurso local renovável. Avalia o estresse imposto ao ambiente, quando menor o valor, menor } \\
\text { o estresse causado. }\end{array}$ & ELR & $(\mathrm{N}+\mathrm{F}) / \mathrm{R}$ \\
\hline $\begin{array}{l}\text { Investimento em emergia é uma relação entre recursos provenientes da economia e os recursos gra- } \\
\text { tuitos. Um índice baixo indica que o ambiente provê mais recursos para o processo que a economia } \\
\text { (materiais e serviços). }\end{array}$ & EIR & $\mathrm{F} /(\mathrm{R}+\mathrm{N})$ \\
\hline $\begin{array}{l}\text { Índice de Sustentabilidade: Mede a taxa de sustentabilidade. Valores maiores indicam sustentabi- } \\
\text { lidade por períodos de tempo maior. Um sistema para ser considerado sustentável por longo prazo } \\
\text { deve ter uma baixa carga ambiental e alto rendimento em emergia. }\end{array}$ & ESI & EYL/ELR \\
\hline $\begin{array}{l}\text { Percentual de recursos renováveis: Indica a porcentagem de fluxo de energia que é proveniente de } \\
\text { fontes renováveis. Os sistemas com alto valor deste índice são mais sustentáveis. }\end{array}$ & $\% \mathrm{R}$ & $(\mathrm{R} / \mathrm{Y}) .100 \%$ \\
\hline
\end{tabular}


Com base nos valores dos fluxos ( $R$, $\mathrm{N}$ e F) dos sistemas estudados, é possível aplicar o diagrama ternário (Barrella et al., 2005, Almeida et al., 2005 e Giannetti et al, 2006) para realizar a comparação entre as configurações propostas para os biossistemas de geração de eletricidade

\section{Resultados da análise em emergia}

A análise em emergia tem início com a construção de diagramas de energia utilizando os símbolos da Figura 4. A observação dos diagramas auxilia na identificação dos limites estabelecidos para os sistemas estudados, assim como na identificação de seus principais componentes e das interações entre eles. Nos diagramas são identificados todos os fluxos de material, energia e serviços necessários para a operação dos sistemas. Para a análise em emergia é atribuída uma linha que atravessa as fronteiras dos sistemas que representa um fluxo. Vale lembrar que as fronteiras foram estabelecidas, neste estudo de acordo com a operação de cada sistema. No biossistema da usina autônoma considerou-se a quantidade de insumos necessários para sua implantação e operação. Para os biossistemas integrados os insumos comuns (biodigestor, motogerador).

\subsection{Sistema da usina autônoma}

O diagrama de energia do sistema da usina autônoma é mostrado na Fig. 1, onde podemos observar todos os fluxos de energia que circulam no sistema e as interações do sistema com o meio ambiente, esta figura foi adaptada do trabalho de Ometo et al, 2006, de onde foram retiradas as trocas financeiras com o mercado, os impostos e a criação de gado, e incluso um sistema de geração de eletricidade através de um motor do ciclo Otto.

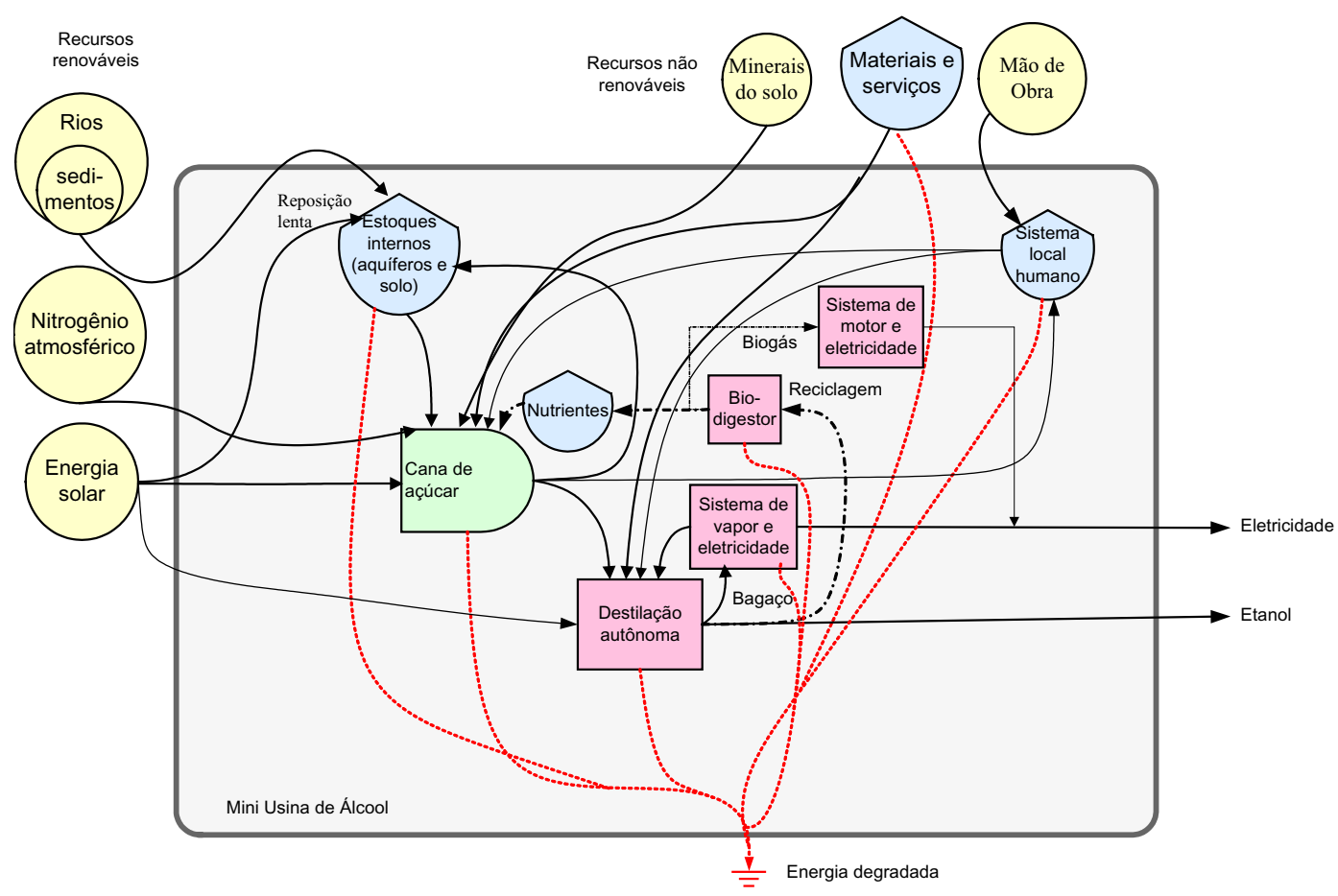

Figura 1. Diagrama de energia do sistema da usina autônoma. (adaptado de Ometto et al, 2006)

A Tabela 2 apresenta os fluxos de material e energia que participam do sistema da usina autônoma. 
Tabela 2. Avaliação da emergia do sistema da usina autônoma (*)

\begin{tabular}{|c|c|c|c|c|c|c|c|}
\hline \begin{tabular}{l}
$\frac{\pi}{0}$ \\
\hdashline
\end{tabular} & Descrição & 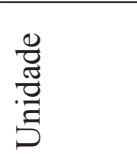 & $\begin{array}{l}0 \\
\text { D } \\
\text { 范 }\end{array}$ & /(un/ano) & $\begin{array}{l}\text { Emergia por } \\
\text { unidade } \\
\qquad \text { (sej/un) }\end{array}$ & $\begin{array}{l}\text { Emergia } \\
\text { /(sej/ano) }\end{array}$ & $\begin{array}{l}\% \\
/(\text { sej/sej) }\end{array}$ \\
\hline & Fase de Implantação & & & & & & \\
\hline 1 & Mudas & g/ano & $\mathrm{R}$ & $4,30 \cdot 10^{7}$ & $1,47.10^{9}$ & $6,32 \cdot 10^{16}$ & $1 \%$ \\
\hline 2 & Perda de solo & $\mathrm{J} / \mathrm{ano}$ & $\mathrm{N}$ & $6,15.10^{12}$ & $7,38.10^{4}$ & $4,54 \cdot 10^{17}$ & $8 \%$ \\
\hline 3 & Equip. e infraestrutura & \$/ano & $\mathrm{F}$ & $2,64 \cdot 10^{5}$ & $3,70.10^{12}$ & $9,76.10^{17}$ & $17 \%$ \\
\hline 4 & $\begin{array}{l}\text { Aço para construção dos } \\
\text { reatores e filtros UASB }\end{array}$ & g/ano & $\mathrm{F}$ & $9,43 \cdot 10^{4}$ & $1,80.10^{9}$ & $1,70.10^{14}$ & $<1 \%$ \\
\hline 5 & $\begin{array}{l}\text { Mão de obra } \\
\text { Fase de Operação }\end{array}$ & $\mathrm{J} / \mathrm{ano}$ & $\mathrm{F}$ & $9.63 .10^{10}$ & $4,30.10^{6}$ & $4,14.10^{17}$ & $7,0 \%$ \\
\hline 6 & Precipitação & $\mathrm{J} / \mathrm{ano}$ & $\mathrm{R}$ & $8,86.10^{13}$ & $1,82 \cdot 10^{4}$ & $1,61 \cdot 10^{18}$ & $29 \%$ \\
\hline 7 & Nutritentes (rocha mãe) & g/ano & $\mathrm{R}$ & $2,69.10^{7}$ & $3,00 \cdot 10^{9}$ & $8,07.10^{16}$ & $1 \%$ \\
\hline 8 & Nitrogênio (atm) & $\mathrm{J} /$ ano & $\mathrm{R}$ & $1,05.10^{7}$ & $4,61 \cdot 10^{9}$ & $4,82 \cdot 10^{16}$ & $<1 \%$ \\
\hline 9 & Água de aquífero & $\mathrm{J} /$ ano & $\mathrm{R}$ & $3,69.10^{9}$ & $1,10.10^{5}$ & $4,06 \cdot 10^{14}$ & $<1 \%$ \\
\hline 10 & Insumos & g/ano & $\mathrm{F}$ & $4,88 \cdot 10^{7}$ & $3,80.10^{9}$ & $1,86.10^{17}$ & $3 \%$ \\
\hline 11 & Defensivos agrícolas & g/ano & $\mathrm{F}$ & $3,59 \cdot 10^{6}$ & $1,48.10^{9}$ & $5,31 \cdot 10^{15}$ & $<1 \%$ \\
\hline 12 & Mão de obra & $\mathrm{J} /$ ano & $\mathrm{F}$ & $3,66.10^{11}$ & $4,30 \cdot 10^{6}$ & $1,58.10^{18}$ & $28 \%$ \\
\hline 13 & Operações agrícolas & \$/ano & $\mathrm{F}$ & $1,10.10^{4}$ & $3,70.10^{12}$ & $4,08 \cdot 10^{16}$ & $1 \%$ \\
\hline 14 & Manutenção & $\$$ /ano & $\mathrm{F}$ & $4,85 \cdot 10^{4}$ & $3,70.10^{12}$ & $1,79.10^{17}$ & $3 \%$ \\
\hline & Emergia Total & & & & & $5,63 \cdot 10^{18}$ & $100,0 \%$ \\
\hline
\end{tabular}

(*) RETIRADO DE SILVA, 2009

\subsubsection{Análise em emergia da usina autônoma}

A emergia total do sistema da usina autônoma tem valor de $5,63.10^{18} \mathrm{sej} /$ ano. Aproximadamente $8 \%$ sej/sej de recursos não renováveis são utilizados, $32 \% \mathrm{sej} / \mathrm{sej}$ são de recursos renováveis e $60 \% \mathrm{sej} / \mathrm{sej}$ dos recursos da economia.

A unidade funcional adotada foi 1 MWh de eletricidade. A produção de eletricidade excedente anual da usina é de $2,65.10^{13}$ $\mathrm{J}$, e sua transformidade é de $2,12.10^{5} \mathrm{sej} / \mathrm{J}$.

\subsection{Sistema da ETE}

A Figura 2 a seguir apresenta o sistema de biodigestão da ETE estudada por Bjorklund, et al, 2000.

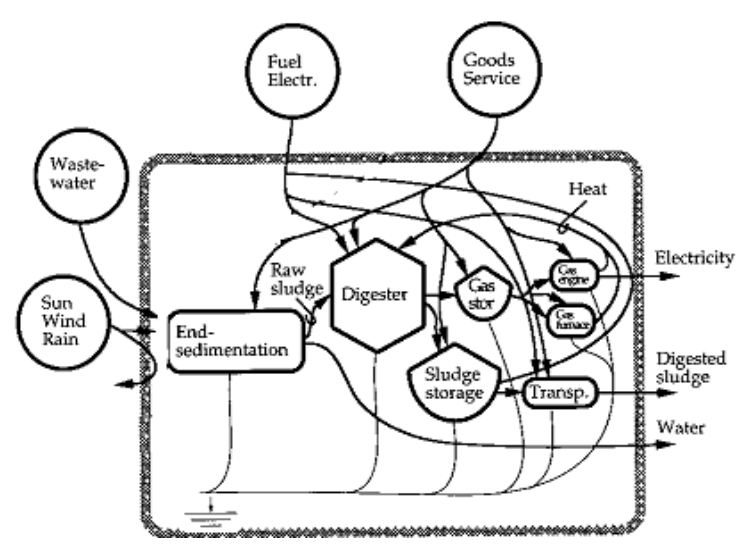

Figura 2 - ETE de Uppsala, Suécia (adptado de BJORKLUND, et al, 2000)

A Tabela 3 apresenta os fluxos de material e energia que participam do sistema da ETE de Uppsala, Suécia, estudada por Bjorklund et al. 2000. 
Tabela 3 - Avaliação da emergia da ETE

\begin{tabular}{|c|c|c|c|c|c|c|c|}
\hline $\begin{array}{l}\frac{\pi}{0} \\
2\end{array}$ & Descrição & 宽 & 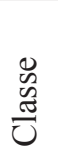 & $\begin{array}{l}\text { Valor } \\
\text { /(un/ano) }\end{array}$ & $\begin{array}{l}\text { Emergia } \\
\text { por unidade } \\
\text { (sej/un) }\end{array}$ & $\begin{array}{l}\text { Emergia } \\
/ \text { (sej/ano) }\end{array}$ & $\begin{array}{l}\% \\
/(\text { sej/sej })\end{array}$ \\
\hline 1 & $\begin{array}{l}\text { Fase de Implantação } \\
\text { petróleo }\end{array}$ & $\mathrm{J} /$ ano & $\mathrm{N}$ & $6,43 \cdot 10^{11}$ & $6.60 .10^{04}$ & $42,4 \cdot 10^{15}$ & $27.8 \%$ \\
\hline 2 & eletricidade & $\mathrm{J} /$ ano & $\mathrm{F}$ & $3,65 \cdot 10^{10}$ & $1.19 .10^{05}$ & $4,3.10^{15}$ & $2,8 \%$ \\
\hline 3 & ferro & g/ano & $\mathrm{F}$ & $3,76.10^{06}$ & $2.65 .10^{09}$ & $10,0.10^{15}$ & $6,5 \%$ \\
\hline 4 & maquinario & g/ano & $\mathrm{F}$ & $1,40.10^{05}$ & $4.10 .10^{09}$ & $0,6.10^{15}$ & $0,3 \%$ \\
\hline 5 & concreto & g/ano & $\mathrm{F}$ & $1,41 \cdot 10^{07}$ & $7.34 .10^{08}$ & $10,3 \cdot 10^{15}$ & $6,7 \%$ \\
\hline 6 & cobre & g/ano & $\mathrm{F}$ & $2,50 \cdot 10^{04}$ & $6.80 .10^{10}$ & $1,7.10^{15}$ & $1,1 \%$ \\
\hline 7 & insolação & g/ano & $\mathrm{R}$ & $5,10.10^{04}$ & $1.84 .10^{09}$ & $0,1.10^{15}$ & $0,07 \%$ \\
\hline 8 & tijolo & g/ano & $\mathrm{F}$ & $1,05.10^{06}$ & $2.52 .10^{09}$ & $2,6.10^{15}$ & $1,7 \%$ \\
\hline 9 & pavimento superficial & g/ano & $\mathrm{F}$ & $1,16.10^{06}$ & $4.74 .10^{08}$ & $0,5 \cdot 10^{15}$ & $0,3 \%$ \\
\hline 10 & serviço & $\mathrm{SEK} /$ ano & $\mathrm{F}$ & $2,98.10^{05}$ & $2.15 .10^{11}$ & $64,0.10^{15}$ & $42,1 \%$ \\
\hline \multirow[t]{2}{*}{11} & mão de obra & SEK/ano & $\mathrm{F}$ & $7,32 \cdot 10^{04}$ & $2.15 .10^{11}$ & $15,710^{15}$ & $10,3 \%$ \\
\hline & Emergia Total & & & & & $152.10^{15}$ & $100,0 \%$ \\
\hline
\end{tabular}

\subsubsection{Análise em emergia da ETE}

A emergia total do sistema da usina autônoma tem valor de $5,63.10^{18} \mathrm{sej} /$ ano. Aproximadamente 27,8\% sej/sej de recursos não renováveis são utilizados, $0,07 \% \mathrm{sej} / \mathrm{sej}$ são de recursos renováveis e 72,13\% sej/sej dos recursos da economia.

A unidade funcional adotada foi $1 \mathrm{~J}$ de eletricidade. A produção de eletricidade excedente anual da usina é de $4,9.10^{11} \mathrm{~J}$ e sua transformidade é de $3,1.10^{5} \mathrm{sej} / \mathrm{J}$.

Tabela 4. Comparação entre as transformidades e custos dos biossistemas

\begin{tabular}{lcc}
\hline Biossistema & $\begin{array}{c}\text { Energia } \\
\text { Gerada / } \\
\text { MWh }\end{array}$ & $\begin{array}{c}\text { Transformidade } \\
\text { sej/J }\end{array}$ \\
& $7,17.10^{3}$ & $2,12.10^{5}$ \\
\hline Usina autônoma & $4,9.10^{9}$ & $3,05.10^{5}$ \\
\hline
\end{tabular}

As transformidades apresentadas na Tabela 4 indicam que o sistema da usina autônoma é o que possui menor valor. Ainda observa-se que a transformidade da usina autônoma é próxima ao valor identificado por Odum (1996) que é de 2,00.105 sej/J.
Essa análise não implica em afirmar que os sistemas se comportam dessa mesma forma quando comparamos outros produtos, pois essa discussão trata somente da geração de eletricidade.

\subsection{Cálculo dos indicadores}

Como podemos observar nas Tabelas 2 e 3 a emergia total é composta por três classes de recursos: $\mathrm{R}, \mathrm{N}$ e $\mathrm{F}$, a partir dos quais é possível calcular os indicadores em emergia (ODUM, 1996). Os indicadores obtidos no estudo da usina autônoma foram comparados com aqueles obtidos na ETE, como se visualiza na Tabela 5.

De acordo com o índice EYR (Tabela 5), podemos verificar que o sistema da usina autônoma apresenta melhor rendimento em emergia, pois utiliza uma proporção maior de recursos locais renováveis e não renováveis $(\mathrm{R}+\mathrm{N})$ em relação ao investimento econômico.

O índice de EIR (Tabela 5) indica que o sistema da usina autônoma apresenta-se mais competitivo. O investimento de recursos da economia em relação aos recursos naturais utilizados na usina autônoma é menor. 
Tabela 5. Resumo dos índices em emergia

\begin{tabular}{lll}
\hline Índices em emergia & \multicolumn{1}{c}{$\begin{array}{c}\text { Usina } \\
\text { autônoma }\end{array}$} & ETE \\
\hline $\begin{array}{l}\text { Rendimento em emergia } \\
\text { (EYR) }\end{array}$ & 1,67 & 1,39 \\
$\begin{array}{l}\text { Investimento em emergia } \\
\text { (EIR) }\end{array}$ & 1,50 & 2,58 \\
$\begin{array}{l}\text { Carga ambiental (ELR) } \\
\begin{array}{l}\text { Indice de sustentabilidade } \\
\text { (ESI) }\end{array}\end{array}$ & 0,79 & 1519 \\
$\begin{array}{l}\text { Percentual de Energia } \\
\text { Renovável (\%R) }\end{array}$ & 32,02 & 0,0009 \\
\hline
\end{tabular}

O índice de carga ambiental ELR (Tabela 5), avalia o estresse ambiental, quanto menor o valor deste indicador, menor o estresse imposto ao ambiente (BROWN e ULGIATI, 2002). Verifica-se que o resultado obtido pelo sistema da usina autônoma $(2,12)$ representa que a energia solar dos recursos não renováveis e dos recursos advindos do sistema econômico é 2,12 vezes maior que a energia solar equivalente dos recursos renováveis utilizados, indicando uma baixa carga ambiental, sendo menor que o valor da ETE, indicando ser o sistema que possui menor estresse ambiental.

O índice de sustentabilidade ESI (Tabela 5), determinado para a usina autônoma, indica a necessidade de melhorias, a fim de aumentar a sustentabilidade dos ciclos. Ao compararmos esses valores, o índice do sistema da usina autônoma apresentou-se maior do que o valor do sistema da ETE, indicando ser o sistema da usina autônoma sustentável por maior tempo.

$\mathrm{O}$ índice de emergia renovável \% $\mathrm{R}$ (Tabela 5) indica o percentual de energia renovável envolvida no processo. De acordo com o protocolo de Kyoto (MRE, 1997), que estabelece que até 2010 o uso de fontes de energia renovável deve alcançar $10 \%$ da matriz energética (BRAGA et al, 2002), verifica-se nesse estudo que a ETE apresenta poucas fontes de energia renovável, seu índice é de $0,0657 \%$, sendo inferior ao mínimo estabele- cido (10\%). Já a de usina autônoma apresenta maior percentual, com índice de 32,02\% de energia renovável de sua cadeia produtiva de seus fluxos em emergia.

A comparação dos valores dos indicadores encontrados para os sistemas indica que a geração de eletricidade do sistema da usina autônoma oferece menor impacto ao ambiente do que a ETE. A ETE utiliza maior quantidade de recursos (transformidade) para gerar a mesma quantidade de eletricidade, este sistema utiliza principalmente recursos provenientes da economia (Tabela 3). A distribuição dos fluxos no sistema de usina autônoma (Tabela 2), entre R, N e F mostra melhor aproveitamento dos recursos locais e gratuitos por este sistema, o que se reflete nos valores dos indicadores calculados.

Utilizando o diagrama ternário em emergia (BARRELLA et al, 2005, ALMEIDA et al, 2005 e GIANNETTI et al, 2006) para comparação entre os sistemas estudados, observa-se (Figura 3) que o sistema de geração da usina autônoma está localizado próximo à linha de ESI=1.

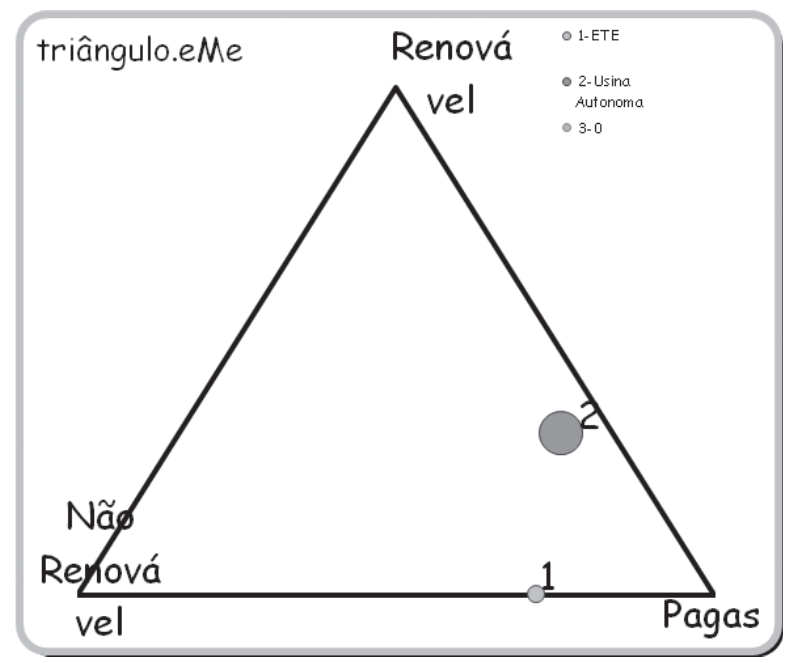

Figura 3. Diagrama ternário em emergia dos sistemas estudados

A representação do triângulo da Figura 3 tem o significado de que o sistema da usina autônoma apresenta maior índice de sustentabilidade. 
As dimensões dos círculos que de cada configuração são proporcionais a quantidade de emergia total empregada. Observa-se que o sistema da ETE utiliza maior fluxo em emergia que o sistema comparado.

É possível ainda com a análise do diagrama ternário visualizar o uso de recursos dos sistemas, ou seja, quanto mais distante do vértice Renovável, menor é a quantidade de fluxos renováveis no sistema, o que corrobora com o resultado dos indicadores de sustentabilidade, mostrando que o sistema da usina autônoma utiliza maior percentual de fluxos renováveis comparando ao outro sistema.

\section{CONCLUSÕES}

\subsection{Quanto ao uso de recursos}

De acordo com os resultados, verificamos que os sistemas apresentam índices relativamente distintos, onde o sistema de usina autônoma apresenta melhor desempenho.

Por meio da representação gráfica no diagrama ternário em emergia (Figura 3), a interpretação dos resultados dos índices em emergia se torna mais rápida, por ser esta uma ferramenta visual. Nota-se que a posição ocupada pelo ponto que representa o sistema da usina autônoma, apresenta melhor desempenho ambiental que o sistema da ETE por estar mais próxima da linha de ESI $=1$, contudo os sistemas comparados se encontram na mesma região, não sendo conclusivo.

A análise em emergia permite ainda a comparação da transformidade (intensidade dos fluxos). Os sistemas analisados apresentam transformidades da mesma ordem de grandeza para a geração de eletricidade, sendo que a transformidade para a o sistema da ETE é aproximadamente $44 \%$ sej/sej maior que o sistema da usina autônoma.

Analisando a transformidade, o sistema com melhor desempenho é o da usina autônoma.

\section{REFERÊNCIAS}

ALMEIDA, C.M.V.B.; BARRELLA, F.A.; GIANNETTI, B.F., 2005 - Emergetic ternary diagrams: five examples for application in environmental accounting for decision-making. Journal of Cleaner Production, v 15, n. 1, .p. 63-74.

BARRELLA, F.A.; ALMEIDA, C.M.V.B.; GIANNETTI, B.F., 2005 - Ferramenta para tomada de decisão considerando a interação dos sistemas de produção e meio ambiente. Revista Produção, v 15, n.1, p. 87-101.

BJÖRKLUND, J,; GEBER, U.; RYDEBERG, T., 2000 - Emergy Analysis of Municipal Wastewater treatment and generation of electricity by digestion of sewage sludge. Resources, Conservation and Recycling, 31, p.293-316.

BRAGA, B.; HESPANHOL, I.; CONEJO, J. G. L; BARROS, M. T. L; SPENCER, M.; PORTO M.; NUCCI, N.; JULIANO, N.; EIGER, S. - Introdução à Engenharia Ambiental. São Paulo, Prendtice Hall, 2002.

BROWN, MT.; ULGIATI, S., 2002 - Emergy Measures of Carrying Capacity to Evaluate Economic Investments, Population and Environment. A Journal of Interdisciplinary Studies, v. 22, n. 5.

BROWN, M. T.; McCLANAHAN, T.R., 1996 - Emergy analysis perspectives of Thailand and Mekong River dam proposals, Ecological Modeling, 91,p.105-130.

GIANNETTI, B. F.; BARRELLA, F. A.; ALMEIDA, C. M. V. B., 2006 - A combined tool for environmental scientists and decision makers: ternary diagrams and emergy accounting, Journal of cleaner production, 14, p.201-210. 
MINISTÉRIO DAS RELAÇÕES EXTERIORES., 1997 - Protocolo de Quioto à convenção sobre mudança do clima. Traduzido pelo Ministério da Ciência e Tecnologia.

ODUM, H.T., 1996 - Environmental accounting : emergy and environmental decision Making. New York: John Wiley \& Songs, p.370.

OMETTO, A. R, CORSINI, R., ORTEGA, H., 2006 -. Mini-usinas de álcool integradas :avaliação emergética. Campinas:, Faculdade de Engenharia de Alimentos, Universidade Estadual de Campinas.
SILVA, C.C., 2009 - A Atribuição de custos em sistemas energéticos agropecuários: uma Análise em emergia, termoeconomia e economia/ Carlos Cezar da Silva; orientador prof. Dr. José Aquiles Baesso Grimoni.-São Paulo, 156 pg. Tese (Doutorado - Programa de Pós-Graduação em Energia) EP / FEA / IEE / IF da Universidade de São Paulo. 